\title{
Design as Dialogue - a New Design Framework
}

\author{
Arminda Lopes \\ a.g.lopes@1eedsmet.ac.uk \\ Leeds Metropolitan University \\ Innovation North \\ Faculty of Information \& Technology
}

\begin{abstract}
In this paper, we examine some traditional ways of designing and we present some guidelines for a different perspective on design: design understood as a process of dialogue and explicit knowledge sharing. There is no standard definition of design it will vary according to perspective. Traditionally, the term design referred to industrial design. This argument is based on Walker (1989) consideration: "(As far as many scholars are concerned, design is industrial design.)" Industrial design concentrates on the product's functionality and its appearance as an object. Design as dialogue requires an emphasis on the process of communication between multidisciplinary teams. We will provide a framework based on dialogue which will improve the process of design associated with the development of flexible design objects.
\end{abstract}

\section{Introduction}

Design is a complex process. There isn't a single definition of design - it can be understood from different perspectives. Designers rarely work alone. They cooperate with others, interacting with groups of people who have different ways of looking at the design problem and the design solution. They bring different knowledge to the design project, and differing viewpoints, expectations and ambitions.

Dialogue is also a complex process without a unique definition. Ellinor (1995) argues "dialogue is about what we value and how we define it. It is about discovering what our true values are, about looking beyond the superficial and automatic answers to our questions. Dialogue is about expanding our capacity for attention, awareness and learning with and from each other. It is about exploring the frontiers of what it means to be human, in relationship to each other and our world".

The goal of this paper is to present some guidelines based on the perspective of design as dialogue. We consider some definitions of design and observations from the literature; we consider three specific usages of the word design: designed object, design process and design discipline. We describe a way of thinking about design: design as dialogue, explaining in what ways this is the case and the benefits of this perspective: We initiate a discussion of a framework based on this perspective, which would help to simplify the design area, and to facilitate the dialogue process. We conclude by highlighting the key research issues and outlining our work in progress in this area.

Please use the following format when citing this chapter:

Lopes, A., 2006, in IFIP International Federation for Information Processing, Volume 221, Human Work Interaction Design: Designing for Human Work, ed. T. Clemmensen, Campos, P., Onngreen, R., Petjersen, A1., and Wong, W., (Boston: Springer), pp. 241-250 


\section{What is Design?}

Determining what is meant by design is not straightforward. The word "design" has different meanings according to the designer's community, the context in which the word is used and the speaker's and listener's perspectives: whether economic, cultural, social, or aesthetic.

Most of our conceptions of design come from industrialisation. This claim is based on Bayley (1982) who considers "the origin of design with the advent of industrialization and mass production methods." In general, design is the act of working out the form of something, for example by making a sketch, outline or plan.

Dictionary definitions also focus on modelling and planning. For example, according to 21 st Century Dictionary, design (noun) is "a plan, drawing or model showing how something is to be made. Design (verb): to develop or prepare a plan, drawing or model of something before it is built or made."

The Concise Oxford English Dictionary defines design (noun) as "a plan or drawing produced to show the look and function or workings of something before it is build or made. Design (verb): decide upon the look and functioning of (something), especially by making a detailed drawing of it; do or plan (something) with a specific purpose in mind."

Those definitions overlap, the difference being that the concepts of aesthetic and functionality included in the second one.

However, the etymology of design goes back to the Latin de+signare meaning distinguishing it by a sign, giving it significance, designating its relation to other things, owners and users.

By analogy, the roots of the word dialogue come from the Greek words dia and logos. Dia means "through"; logos translate to "word", or meaning. Isaacs (1999) pointed out that "In essence, a dialogue is a flow of meaning."

We really need to state some definitions about design in order to understand why being design a fertile and challenging subject it is complex and also it need to a new framework, the dialogue perspective which will allow establishing new ways of understanding design.

\subsection{Observations about Design}

In the literature relating to this area we can find some observations that have been made about design and which are important to understand why design is an activity fundamental to human action and why design as dialogue is a useful framework.

Design history is important because narrations of design have a feedback effect in the way it can influence the guidelines of the future of design. Doordan (1995) pointed out that design history, like other areas of historical inquiry, "is constantly reconfiguring itself, reformulating its subject matter, and redefining its methods in order to contribute in a vital way to the discussion of contemporary issues and opportunities." His main focus is that design is a process of change itself. Designers will communicate the changes by creating it, contributing to innovation and using design as a social and cultural process. Walker (1989) considers design as "a fertile and challenging subject for the historian because it occurs at a point of intersection or mediation between different spheres, which is between art and industry, creativity 
and commerce, manufacturers and consumers". For him, design can also be considered as an aspect of human culture.

Buchanan (1998) refers the cultural, technological, communicative aspects of design. He argues that design "is a liberal art of technological culture, concerned with the conception and planning of all of the instances of the artificial or humanmade world: signs and images, physical objects, activities and services, and systems or environments". He considers that there are three great expressions of design thinking in the twentieth century: engineering, marketing and the forms of graphic and industrial design.

Multidisciplinary is an important characteristic in design as in dialogue. Matthews (1998) said that " $a$ simplest engineering design involves several different engineering disciplines. Design is sometimes intangible, repetitive and iterative; it contains lot of the world's complexity". Pugh (1996) design "it is an activity that integrates the bodies of knowledge present in the arts and sciences".

Julier (2000) considers design as " a focus of leisure and consumption; it has become a source of public entertainment and serves as an indicator of economic performance, cultural regeneration and social-well-being."

Preece (2002) referring the design process, pointed out that the aim of interaction design is "bringing usability into the design process, which means developing interactive products that are easy, effective and enjoyable to use, from the user's perspective".

Findeli considers that design can have different definitions depending on if it considered to be an idea, knowledge, a project, a process, a product, or even a wayof-being.

These observations are reflecting different aspects of design: change, culture, communication, multidisciplinary, complexity and usability. All these observations are important aspects related with dialogue as well as design which we will state in this paper.

\section{A Way of Thinking about Design: Design as Dialogue}

Design can be understood from different perspectives, as stated earlier. It involves communication between people through a dialogue.

Gadamer (1979) cited by Smith (2001) describes conversation as: "[It] is a process of two people understanding each other. Thus it is a characteristic of every true conversation that each opens himself to the other person, truly accepts his point of view as worthy of consideration and gets inside the other to such an extent that he understands not a particular individual, but what he says."

Design as a communication process is a dialogue or a conversation (we use both, dialogue and conversation, referring to the same meaning) between designer and other participant in the process.

\subsection{What is Design as Dialogue?}

Design as dialogue is a communication process between all the participants and elements of design. All designs tell something, through text, image, symbols, or 
styles. It is a conversation between designer and user. According to Isaacs (1999) "dialogue is a conversation in which people think together in relationship. Thinking together implies that you no longer take your own position as final".

Designers communicate directly with their users through the appropriate placement of visible cues, hints, and agreements. They use a narrative (a story, an interpretation of some aspects of the designed object).

Dialogue allows us to share meaning, look for understanding, make connections and interpretations, and inquire into assumptions. It invites us to discover. Design is also about all of this.

Dialogue can develop common values and allow participants to express their own interests. It expects that participants will grow in understanding and may decide to act together with common goals. Through dialogue, participants can question and revaluate their assumptions.

\subsection{Elements of Dialogue (Communication, Meaning, Interpretation, Understanding)}

Design as dialogue can only be understood in the context of communication, interpretation, meaning, understanding, learning, cooperation... We will state some of these elements which will allow analysing the dialogue between designers.

In a very broad sense, communication means to give and exchange information. And in this sense, normally we refer to communication among people or among nonhuman animals. People communicate with words and with pictures, and also communicate in many different languages.

Communication is also concerned with communication across cultures. Communication from a cultural perspective includes individuals, meanings (as theoretical meanings, values, norms, and ethics) and vehicles (as language and behaviour). Hall (1997) pointed out that "to understand culture we need to explore how meaning is produced through the signifying practices of language."

Through dialogue, searching out meaning, we become more critical because using language we are not just expressing ourselves alone, but with others. Language and discourse are not just means of expression but they make possible the interaction between the participants. In dialogue, when one person says something, the other person does not in general respond with exactly the same meaning as that seen by the first person. This difference in meaning allows participants to see something new and to integrate multiple perspectives and shared meaning. According to Crystal (1997) meaning "is a basic notion used in language study in two main ways: first determining the signification of a message (...) secondly, meaning is used as a way of analysing the structure of language..."

Isaacs (1999) considers that "there are dimensions in our internal world that do not exist in the external in the same way, but which are nevertheless quite important. For instance, our internal world is characterized by interpretation that is our ability to make sense of what we see and hear and experience."

Usually, we believe the ideas we are expressing are the same ideas we initially formed in our own mind. But how our expression is received depends on who is receiving it and the way he interprets it.

An object has an initial impact from its appearance, touch, and feel. Then at a performance level, the focus is on use, on experience with the object. Experience has 
many facets: function, performance, usability and aesthetics. Then there is the interpretation level in the identification of the product with places, feelings, and people.

Dialogue is a way of coming to an understanding and a way of relating to participants. When participants listen to each other and relate, they learn new perspectives, reflect on their views, and develop mutual understanding. It emphasizes listening, learning and the development of shared understanding. In design, understanding who the users are, what tasks they will be performing, how much experience they have, what problems they foresee, what expectations they have for the object will contribute to the quality of the design. These aspects of the design process will be the subject for the dialogue between designers.

\section{How Design is a Dialogue Process}

The word design is used in different ways. The specific usages we will discuss are designed object, design process and design discipline.

When we refer to designed objects the association is frequently with industrial design, a field where designers are able to convey messages, and even propose new ways of living, through the creation of functional objects.

Designed objects focuses on the concept of form and function and creating objects, furniture and tools that serve their purposes and are at the same time aesthetically pleasing.

The design process on the other hand, as Mathews (1998) considers, consists of three established stages: conceptual design; embodiment design; detailed engineering design. In general, a design process contains the following basic key steps: design brief; statement of intent; product design specification; concept design; detail design; manufacturing and testing; sales.

By design discipline we mean the field of endeavour which encompasses many design activities including (but not limited to) planning, urban design, architecture, interior design, product design, graphic design, arts, engineer, performance, music. Every product crafted by humans is the result of design.

Designed Objects as Dialogue: Objects communicate - a well designed object communicates with people by many different messages. A designer can create an object that is articulate; its form announces its function and it actually conveys ideas to those who interact with it.

When first confronted with an object, a user will understand the first idea that the designer intended to convey, and the design will relate further ideas with meaning.

In an object design, there are three components, according to Norman (2004) "usability, aesthetics, and practicality" which interact to convey information about the user's pleasure using the object. Jordan (2000) considers that "once people had become used to having appropriate functionality, they wanted products that were easy to use (...) Having become used to usable products (...) products that people relate to". So, people have relationships with objects and they can dialogue with themselves about the objects. This is possible using Bohm's (1996) observation about dialogue: "a dialogue can be among any number of people, not just two. Even one person can have a sense of dialogue within himself, if the spirit of the dialogue is present." 
Design Process as Dialogue: Dialogue enables understanding the process of design and the communication between participants. According to Bohm (1996) the process of dialogue is a "process of 'awakening', it entails a free flow of meaning among all the participants".

Dialogue begins with an idea as design begins. The key components include the sender, the idea, the evidence that supports that idea, and the sender target. Once the idea has taken some reasonable form, it can be shared.

Design is the process by which the needs of the customer are transformed into a product satisfying these needs. The design process contains the discussion of existing products - people's opinion about products - prototyping - people's feedback, team's conversations, and dialogue with stakeholders. It contains a variety of questions and answers: what is the practical function of the design? What part does appearance play in the design's function? What materials are suitable for the design? What construction methods are appropriate to the design? What are the likely social and environmental effects of the design?

Design includes multidisciplinary teams participating in discussions in the design process.

Design Discipline as Dialogue: The way to interact within this multidisciplinary field is by dialogue. Dialogue can be a strategy that offers us some clues in the situation of diversity. Dialogue is a learning discipline about people and about objects.

The design discipline is concerned with the social, cultural, philosophical study of design. It draws upon approaches from Design History to Cultural Studies.

Design discipline allows the analysis of historical and cultural codes and also to deal with new design challenges. Design by definition allows understanding past and future developments in the field. Since Pre-History, for example, people communicate through pictograms, another mark was the Egyptian civilizations that codify design elements. Historical understanding of an object's significance and value reside in a wide range of influences and ideas, a complex social and cultural mix, a long communication process. Referring to industrial design and understanding it involves an analysis of modern consumption and interpretation of our everyday life which is full of signs and elements of communication.

Dialogue is to explore design as it is. History permits us to understand why design is dialogue (there was always a communication process within it - verbal and visual, for example).

\subsection{Benefits of Thinking of Design as Dialogue}

Thinking about design as dialogue will give us some advantages through a new framework.

Dialogue enables teams to reach higher levels of performance. Higher levels of performance are the result of learning processes and interrelationships between people. The practice of dialogue contributes to the design of objects and systems that clarify all the design process through listening, hearing and participation. Planned actions and interactions are often difficult to predict with clarity and confidence. Dialogue helps us to find connection and meaning within the design process.

Dialogue invites discovery as design does. It develops common values and allows participants to express their own interests and ideas. In dialogue, participants can 
question and re-evaluate their assumptions. Through this process, people are leaming to work together to improve usability and aesthetic in designed objects.

Thinking about design as dialogue also underlines some probable solutions to design complexity.

\section{Framework to Simplify Design Complexity}

The framework based on dialogue will improve the process of design associated with the development of flexible design objects. Essentially, flexible design expands choice, on what, when, where and how design teams design. It will be a reference where each participant, designer and probably user, because a designer is a user, has a role in the changing process of design, solving complex problems giving simple solutions. The framework tries to answer some questions, for example: who are the participants in the design process? How might each dialogue element be relevant in the design/dialogue process? How might each design element (line, shape, texture, space, size colour and value) be relevant in the design/dialogue process? What are the elements contained in the interaction process?

\subsubsection{Facilitation of Design Process}

Dialogue builds learning from thinking together as a design team which means that thinking together builds conceptions that lead to shared understanding. Dialogue facilitates a view of participants as both observers and the observed. Dialogue requires an absence of hierarchy which means dialogue can only occur when design team sees each other as colleagues in a mutual search for deeper insight. Generally, in a design process, there are leaders in the process which could be considerable different with this approach. Dialogue as Isaacs (1999) said, presents "the opportunity to reflect and to be heard, and to reflect further on what it means to be heard." This argument underlines the importance of dialogue on design, through talking together and thinking together without hierarchies.

\subsubsection{Multidisciplinary Dialogue}

Multidisciplinary dialogue can be found in the design teams. Design teams are constituted by different people, with different backgrounds and different perspectives. To understand the behaviour of the group and the designed object it is necessary to recognise cultural and language differences between the participants.

Cushner (1996) considers that Culture consists of interrelated components of material artefacts, social and behavioural patterns and mental products. Culture is something that is made by human beings rather than something that occurs in nature. He defines two kinds of culture: "Objective culture - refers to the visible, tangible aspects of culture, and includes such things as the artefacts people make, the food they eat, the clothing they wear, and the names they give to things; and Subjective culture - refers the invisible, less tangible aspects of a group of people which means people's values, attitudes, norms of behaviour and adopted roles."

Kroeber (1952) refers to culture being produced by the past actions of a group and its members. The members of a culture system share a set of ideas, and especially values. These are transmitted particularly from one generation to another by symbols. 
Kuhnt (2002) considers that culture influences the attitude towards the usability of globally used software products. It can be approached according to the dependence on user's beliefs about usability cultural specific variables or according to the dependence on their cultural background. Sometimes, users may focus either on aspects concerning effectiveness, efficiency or satisfaction when using a product, which rarely happens. The International Standards Organization (ISO) defines usability as: "the effectiveness, efficiency or satisfaction with which specified users achieve specified goals in particular environments." (ISO DIS 9241-11).

The multidisciplinary dialogue can also be found in language. Language is more than a functional means of communication within a culture. Human language reflects how individuals think and interact. If we deal with the interaction process between users and interactive products it requires taking into account a number of independent factors including context of use, type of task, and kind of user. Language can be used with different meaning as Isaacs (1999) pointed out." The first is the voice and language of meaning, the second is the language and voice of feelings and aesthetics, the third is the language and voice of power, the power of our actions." Dialogue includes all three of these voices: meaning, aesthetics, and power. There is a need to understand which language is spoken at each time to engaging in dialogue.

\section{Problems to be Addressed}

Although "Design as Dialogue" seems straightforward it brings some problems which need solutions.

Understanding multidisciplinary design dialogue is not simple because there is complexity in design, complexity in dialogue and complexity in dealing with teams of people in design who have multidisciplinary background.

Specifying context is an important process because context helps to first understand how objects within a universe of discourse or domain discourse, i.e., the set of terms used in a specific discourse, relate to each other to form a coherent whole.

Even so, we consider that the work in progress, specifically the observation and analysis of some case studies, will bring more understanding of the whole the process.

We believe that dialogue is the pathway to interpret and understand the design process contributing to providing guidelines to help the designer community to build designed objects and to review the design process in a simple way.

\section{Conclusion}

Design is complex but can be understood in terms of dialogue. To validate this argument we need to have a deeper understanding of the dialogue process as well as understanding multidisciplinary design dialogue between teams of people with different backgrounds. 
The work in progress aims to gain this understanding providing a framework which could be usable by multidisciplinary design groups to ensure good working practices and to achieve the best and the most comprehensive design for the target community.

The expectations are that through dialogue, designers will be able to reach beyond any differences and disagreements towards a better understanding of how to improve design.

\section{Future Work}

The work in progress is the study of interdisciplinary art and technology teams designing interactive artworks. Teams have different constituencies, for example researchers from art, design, IT, computer science, engineering, architecture, cultural studies, and media studies. Each team's main goal is to look at human-computer interaction $(\mathrm{HCl})$ theory, design and application of interactive technologies. The interactive artwork will allow the analysis of dialogue as well as design process of the interdisciplinary teams.

Analysing the process, communication tools, language, and values will derive guidelines for the support of such processes.

The methods used to collect data for this research will be centred on a qualitative study, a combination of research methods will be used to collect the data, including documentation, case study, interviews and observation.

Discourse analysis will be used to examine modes of speech used in dialogue, used as social narratives to explain the events. All the design process is video recorded, accompanied by textual descriptions; attending to the conversation formulations produced by designers in their dialogue together; observation of designers talking, listening to their conversations and describing their formulations; analysis of the work plans; observation of all the activities which take place and the relationship between activities and designers.

\section{Acknowledgments}

I would like to thanks to supervisors Tony Bryant and Janet Finlay for comments on earlier drafts of this paper and to Leonardo Network for the opportunity they gave to work with them. This work is part of a PhD project partly funded by PRODEP III - Medida 05 / Acção 03 "Formação Avançada de Docentes no Ensino Superior" Código Projecto: 05.03/C/00195.012/03.

\section{References}

1. Bayley, S.: Art and Industry, London, Boilerhouse Project, 1982

2. Bohm, David: On Dialogue, Routledge, London, 1996 
3. Buchanan, R.: "Banzi's dilemma: design in contemporary culture", Design Issues, 1998

4. Concise Oxford English Dictionary, Oxford University Press, 2000

5. Crystal, David: The Cambridge Encyclopaedia of Language, 1997

6. Cushner et al.,; Intercultural Interactions - A practical Guide, Cross-Cultural Research and Methodology, Volume9, Sage Publications, UK, 1996.

7. Ellinor, Linda and Glenna Gerard: Dialogue: Rediscover the Transforming Power of Conversation 1995 Published by John Wiley and Sons Inc, USA.

8. Hall, S.: Representation: Cultural Representation and Signifying Practices, London and Thousand Oaks: Sage, 1997

9. Isaacs, William: Dialogue and the Art of Thinking Together: A Pioneering Approach to Communicating in Business and in Life. Random House, 1999

10. Jordan: Designing Pleasurable Products London Taylor and Francis, 2000

11. Julier, Guy: The Culture of Design, Sage Publications, London, 2000

12. Kroeber and Kluckhohn, C.: Culture: A critical review of concept and definitions, Cambridge, MA: Harvard University Press, 1952.

13. Kuhnt, Thomas Vohringer: The Influence of Culture on Usability, Masters Thesis, Freie Universitat, Berlin, 2002

14. Matthews, Clifford: Case Studies in Engineering Design, Arnold, London, 1998

15. Norman, Donald: Emotional Design: Why We Love (Or Hate) Everyday Things, Published by Basic Books, NY, 2004

16. Preece, Jenny: Interaction Design, John Wiley and Sons Inc, USA. 2002

17. Price, Stuart: Communication Studies, Addison Wesley Longman Limited 1996

18. Smith, M. K.: 'Dialogue and conversation', The Encyclopaedia of Infornal Education, 2001, www.infed.org/bibio/b-dialog.htm

19. Walker John: Design History and the History of Design, Pluto Press, London, 1989

20. 21 st Century Dictionary, Chambers, Harraps Publishers, Ltd 